Recorregut de recerca de geològica i mineralògica per les comarques de l'Alta Ribagorça i del Pallars Jussà: des del Pas de Llevata a Manyanet

Josep Maria Mata-Perelló

Joaquim Sanz Balagué

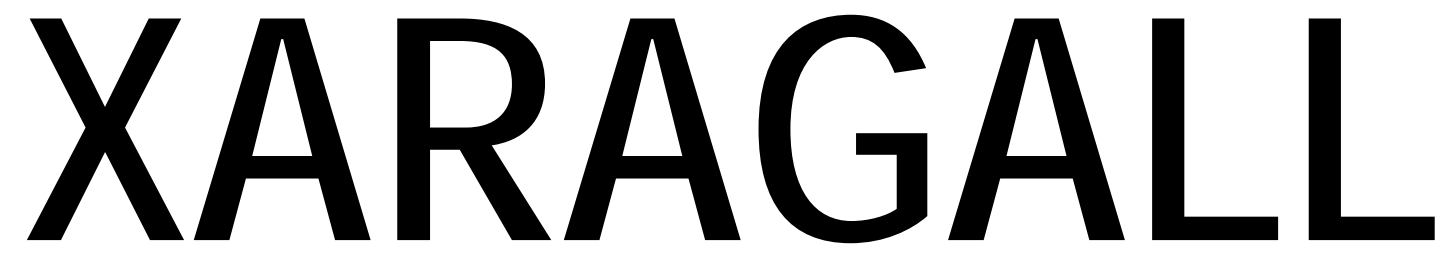

REVISTA DE CIÈNCIES DE LA CATALUNYA CENTRAL

n. 8

AGOST 2015

Com citar l'article: Mata-Perelló, JM.; Sanz Balaguer, J. Recorregut de recerca de geològica i mineralògica per les comarques de I'Alta Ribagorça i del Pallars Jussà: des del Pas de Llevata a Manyanet. A: XARAGALL. Revista de Ciències de la Catalunya Central. 2015. (n.8). ISSN 2013-4479 DL: B.21483-2009. DOI 


\title{
RECORREGUT DE RECERCA DE GEOLÒGICA I MINERALÒGICA PER LES COMARQUES DE L'ALTA RIBAGORÇA I DEL PALLARS JUSSÀ: DES DEL PAS DE LLEVATA A MANYANET
}

\author{
Josep Maria Mata-Perelló \\ Museu de geologia Valentí Masachs, Escola Politècnica Superior d'Enginyeria de Manresa \\ (EPSEM), Universitat Politècnica de Catalunya · BarcelonaTech (UPC), 08272 Manresa, Spain
}

\section{Joaquim Sanz Balagué}

Departament d'Enginyeria Minera i Recursos Naturals (EMRN), Escola Politècnica Superior d'Enginyeria de Manresa (EPSEM), Universitat Politècnica de Catalunya . BarcelonaTech (UPC), 08272 Manresa, Spain

Paraules clau: Sistema Pirinenc, Patrimoni miner

\begin{abstract}
Resum
Itinerari realitzat el 9 d'agost de 2014. En aquesta ocasió, la totalitat del present recorregut de l'itinerari discorrerà pel Sistema Pirinenc i més concretament per la denominada Zona Axial Pirinenca (pels denominats Apilaments Antiformes de la Zona Axial Pirinenca).

Així, el recorregut podria iniciar-se a per les immediacions de la població de Taüll, concretament al Pas de Llevata, situat dintre de l'esmentada Zona Axial Pirinenca (Apilaments Antiformes de la Zona Axial Pirinenca). A partir d'aquest indret i fins a la fi del recorregut, ens anirem sempre desplaçant per aquesta subunitat dels Pirineus, fins a la fi del recorregut.

Així, anirem trobant afloraments dels materials paleozoics. En un principi, veure els materials de I'Ordovicià (fonamentalment esquistos i quarsites: Tanmateix trobarem afloraments del Silurià (les conegudes pissarres negres). I, finalment trobarem els materials del Devonià (tant els carbonatats com els pissarrencs). Molt sovint, aquets materials els veurem recoberts per terrenys cenozoics del Neogen (generalment del Pleistocè i de l'Holocè), de caràcter eminentment detrítics, d'origen glacial.

Per altra banda, aquest recorregut es realitzarà a través de dues comarques de la Regió dels Pirineus. Començarà a I'Alta Ribagorça (al terme de Barruera), iniciant-se-se des de prop de Taüll (Pas de Llevata).. A partir d'aquest indret, el recorregut es situarà dintre del Pallars Jussà, pel terme de Sarroca de Bellera; tot i que abans, aquest sector pertanyia al terme de Benes, ara integrat al de Sarroca, però antuvi situat a l'Alta Ribagorça.
\end{abstract}




\section{Objectius fonamentals}

Els objectius fonamentals que es pretenen aconseguir en aquest itinerari, es poden concretar en els següents aspectes generals:

1. Observació dels materials paleozoics (fonamentalment de l'Ordovicià, del Silurià i del Devonià), que trobarem al llarg de tot el recorregut de l'itinerari, entre les poblacions de Taüll i Manyanet.

2. Observació de l'estructura d'aquesta subunitat pirinenca, al llarg de tot el recorregut de I'itinerari.

3. Reconeixement de diverses mineralitzacions, que anirem trobant al llarg del recorregut, si s'escau.

4. Estudi i descripció de les diferents explotacions mineres que es vagin trobant, al llarg de I'itinerari.

5. Visió de l'impacte produït sobre el Medi Natural, com a conseqüència de les explotacions mineres anteriors. I, tanmateix de la restauració del mateix.

6. Valorització del diferents indrets del Patrimoni Geològic i Miner que anem trobant al llarg del recorregut. En aquest recorregut, ens centrarem fonamentalment en el Patrimoni Geomorfològic associat al glacialisme.

\section{Antecedents}

Per la nostra banda, no tenim gaires antecedents bibliogràfics relatiu a la totalitat del recorregut d'aquest itinerari. Hi ha, però, uns antecedents nostres, molt propers en el temps; un relatiu al tram inicial; es tracta de MATA - PERELLÓ (2013a). I un altre relatiu a la totalitat del recorregut: MATA - PERELLÓ (2013c), molt semblant al que ara presentem. També n'hi ha un altre de similar, relatiu al darrer tram; es tracta de: MATA - PERELLÓ (2013b). Tret d'aquests, no en tenim cap més.

Pel que fa a la descripció de les mineralitzacions situades a les comarques per les quals discorre l'itinerari, farem esment d'uns altres treballs nostres; concretament de MATAPERELLÓ (1991) i de MATA-PERELLÓ i SANZ BALAGUÉ (1988 i 1993).

I, finalment, pel que fa a l'estructura geològica de la zona per la qual discorre l'itinerari, farem esment dels treballs generalistes de: GUIMERÀ et altri (1982) i de RIBA et altri (1976), tots dos referents al conjunt dels Països Catalans.

Tots aquests treballs i d'altres, figuren esmentats per ordre alfabètic a l'apartat dedicat a la BIBLIOGRAFIA ESMENTADA. 


\section{Recorregut de l'itinerari}

Així, el recorregut de l'itinerari, s'iniciarà a la Vall de Boí o Vall del Noguera de Tor, concretament per les immediacions de poble de Taüll, des d'on es sortirà, per tal d'anar cap a les Pistes d'Esquí. Tot seguit, després d'anar cap a les Pistes d'Esquí, on ens caldrà demanar autorització, per tal de continuar per les pistes (normalment tancades) que condueixen cap al Llevata, cap on ens caldrà anar. En aquest tram, efectuarem una nova aturada.

Després, ens caldrà continuar a peu, baixant des del Pas de Llevata, tot seguint el barranc dels Plans, anant cap els Estanyets, per on farem una nova aturada. Després, ens caldrà seguir cap el Sud, per tal d'arribar al riu de Manyanet.

A partir d'aquest indret, ens caldrà seguir-lo, anant sempre cap al Sud, per tal d'arribar fins a I'antic poble de Manyanet, per on finalitzarà el recorregut d'aquest itinerari. En aquest tram, farem algunes parades.

\section{Advertiments previs}

Com en altres recorreguts de RECERCA GEOLÒGICA I MINERALÒGICA... si es disposa del temps suficient, poden efectuar-se passant per totes les parades i filloles. En cas contrari, recomanem prescindir de les anomenades PARADES - CONDICIONALS.

També cal fer esment, de que alguns trams del recorregut es faran per camins en mal estat de conservació, per la qual cosa serà millor fer-los a peu. Tot i així, la major part del recorregut, caldrà fer-lo a peu, tot baixant des del Pas de Llevata cap a la població de Manyanet.

En qualsevol cas, i com és natural, cal tenir sempre una cura molt especial de respecte a la natura, al llarg de tot el recorregut de l'itinerari.

\section{Descripció de l'itinerari}

Com de costum, estructurarem el recorregut de l'itinerari en una sèrie de PARADES, que tot seguit anirem veient. En cadascuna d'aquestes aturades farem un breu comentari (geològic 0 mineralògic, segons s'escaigui). Per d'altra banda, en cada cas indicarem, entre parèntesi, el full topogràfic on es troba l'aturada. Per fer-ho, utilitzarem els fulls editats per I'Instituto Geográfico y Catastral de España, publicats a l'escala de 1:50.000. En aquest cas, els fulls seran els dos següents: $\mathbf{2 1 3}$ (o del Pont de Suert) i $\mathbf{2 1 4}$ (dit de Sort). Tot i així, la major part de les aturades es troben en aquest darrer full. Així doncs, la relació de les aturades que composen el recorregut d'aquest itinerari, és la següent: 


\subsection{Parada 1. PAS DE LLEVATA, (Boí i Manyanet, termes municipals de Barruera i de Sarroca de Bellera, comarca de l'Alta Ribagorça i del Pallars Jussà). (Full 214).}

Tot i que el recorregut l'haurem iniciat a Taüll, ens caldrà anar cap a I'Estació d’Esquí de Boí Taüll, amb la finalitat d'arribar fins al Pas de Llevata. En arribar-hi, farem la darrera aturada del recorregut d'aquest itinerari. Així, haurem efectuat un recorregut d'uns $3 \mathrm{~km}$ des de l'inici, aproximadament. Cal recordar, que per transitar per aquets camins, cal demanar permís als responsables de l'estació d'esquí que acabem d'esmentar.

En aquest recorregut, hem estat en tot moment dintre de la Zona Axial Pirinenca. Així, haurem trobat, per arreu, afloraments dels materials paleozoics, primer del Devonià (generalment calcaries). Després haurem trobat afloraments del Silurià (pissarres fosques). I finalment, haurem trobat afloraments de I'Ordovicià (esquistos i quarsites). Aquests darrers materials de I'Ordovicià, són els que es troben a l' indret de l'aturada. Molt sovint, aquests materials es troben recoberts per depòsits, generalment glacials del Pleistocè i de l'Holocè.

\subsection{Parada 2. ELS ESTANYETS, COMA DELS ESTANYETS, (Manyanet, actualment forma part del terme municipal de Sarroca de Bellera, del Pallars Jussà i antigament era del terme de Benes, de l’Alta Ribagorça). (Full 214).}

Després de realitzar l'aturada anterior, cal començar a baixar a peu, cap a la Vall de Manyanet. Així, ho farem baixant pel barranc dels Plans. Aviat arribarem al paratge dels Estanyets, per on farem una nova parada, després d'un descens de prop de 250 metres, fets en una mitja hora.

En aquest recorregut, hem circulat en tot moment per la Zona Axial Pirinenca, trobant sempre afloraments dels materials paleozoics de l'Ordovicià. Ocasionalment, també hem trobat afloraments del Silurià. Sovint, hem trobat aquests materials recoberts per terrenys detrítics cenozoics, del Pleistocè i de l'Holocè. Aquests materials cenozoics, tenen un clar origen glacial.

En aquest indret hi ha uns interessants i petits estanys (els Estanyets). Es caracteritzen per tenir una clara morfologia glacial, essent d'origen glacial. Efectivament, ens trobem dintre d'una coma, la qual es relaciona amb un antic circ glacial. (fotografia 1 ). 


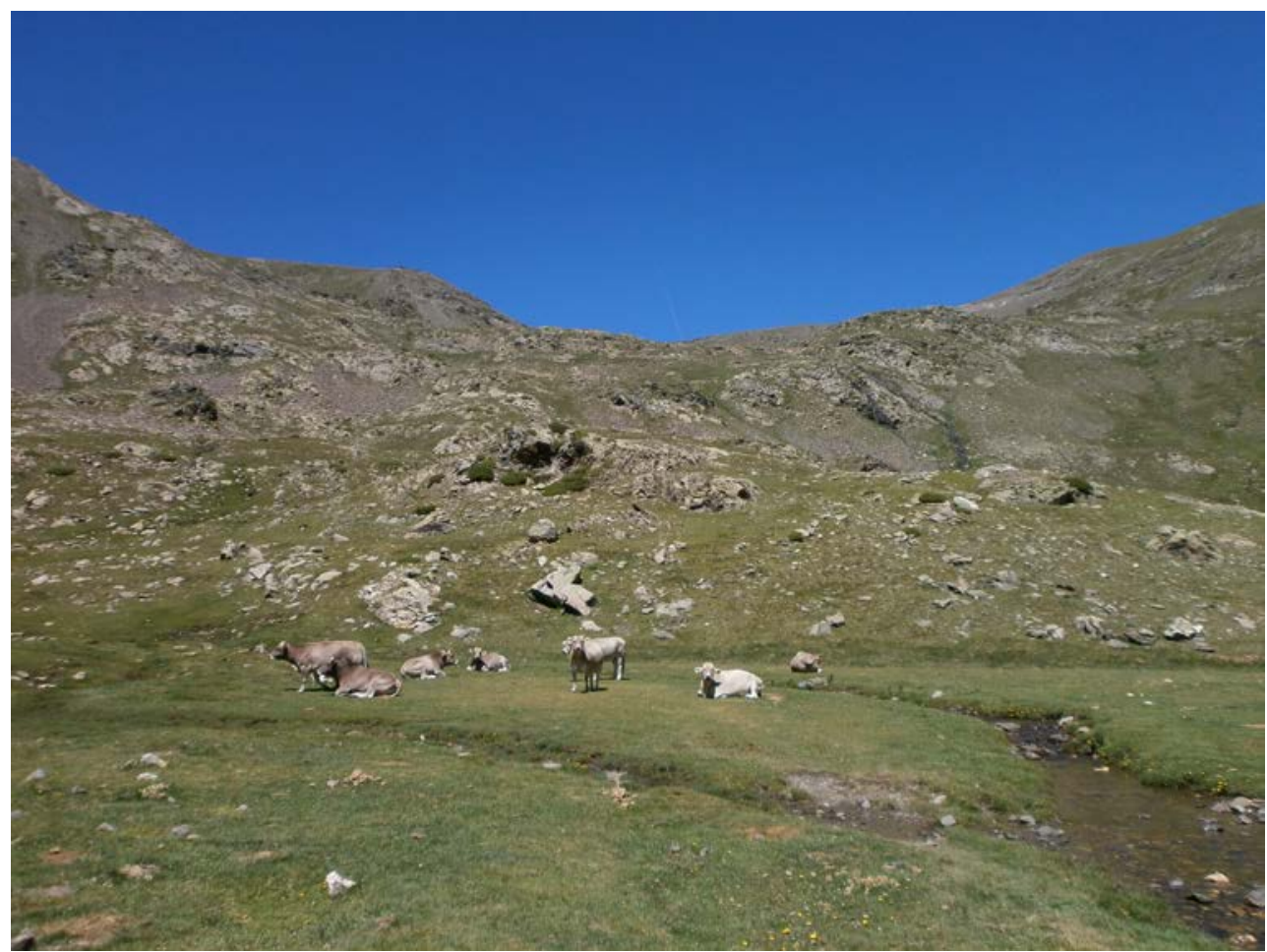

Fotografia 1. Pla dels Estanyets, Llevata. 9 d'agost del 2013

\subsection{Parada 3. CLOT DE LA MINA, (Manyanet, actualment forma part del terme municipal de Sarroca de Bellera, del Pallars Jussà i antigament era del terme de Benes, de I’Alta Ribagorça). (Full 214).}

Després de realitzar l'aturada anterior, cal efectuar un curt recorregut, per la zona dels estanyets, anant cap els Estanys de Llevata. Abans d'arribar-hi, caldrà fer una nova aturada, a menys de 0 ' $5 \mathrm{Km}$ de l'anterior.

En aquest trajecte, hem estat en tot moment dintre de la Zona Axial Pirinenca. Així, haurem trobat afloraments dels materials paleozoics, fonamentalment de l'Ordovicià. Tot i així, en arribar a l'indret de l'aturada, haurem vist afloraments dels materials carbonatats del Devonià. En aquest indret, tot i que no hem trobat cap mina, haurem vist diverses mineralitzacions ferruginoses. Aquestes es localitzen entre els materials del Devonià. Així, haurem vist indicis de GOETHITA (LIMONITA), HEMATITES i SIDERITA. 


\subsection{Parada 4. LA BASSA, (Manyanet, actualment forma part del terme municipal de Sarroca de Bellera, del Pallars Jussà i antigament era del terme de Benes, de I’Alta Ribagorça). (Full 214).}

Després d'efectuar la parada anterior, cal anar cap a llevant, per tal d'arribar fins a la Bassa. En arribar-hi, farem una nova atura, a uns 10 minuts de l'anterior-

En aquest recorregut, hem continuat trobant afloraments dels materials paleozoics esmentats a les aturades anteriors. Aquests formen part dels Apilaments Antiformes de la Zona Axial pirinenca, on estem ara situats.

En aquest indret hi ha un petit estany d'origen glacial. Te molt poca profunditat i poc a poc es va cobrint de sediments neògens, fonamentalment del Pleistocè i de l'Holocè. (fotografia 2).

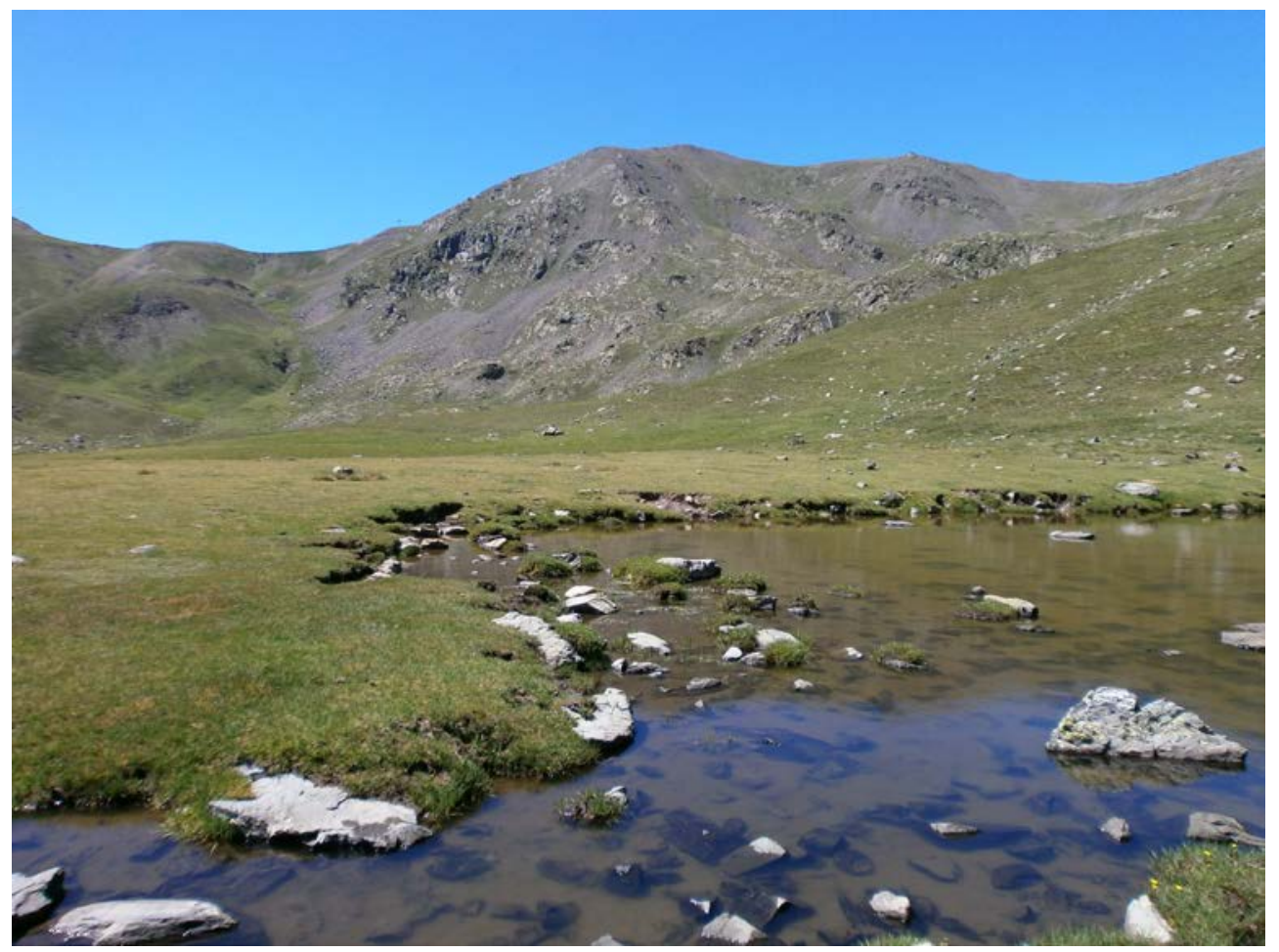

Fotografia 2. La Bassa, Llevata. 9 d'agost del 2013 


\subsection{Parada 5 - CONDICIONAL. CLOT DE LO VEDAT, (Manyanet, actualment forma part del terme de Sarroca de Bellera, del Pallars Jussà i abans ho era del terme de Benes, de I'Alta Ribagorça). (Full 214).}

Després de realitzar l'aturada anterior, cal continuar baixant a peu. Així, ara ens anirem apropant al riu de Manyanet, arribant al Clot de lo Vedat, per on farem una nova parada, si s'escau, després de baixar uns 300 metres més. Possiblement haurem tardat uns 45 minuts en fer-ho.

En aquest trajecte, hem estat en tot moment dintre de la Zona Axial Pirinenca. Així, haurem trobat afloraments dels materials paleozoics, fonamentalment de l'Ordovicià. Tot i així, en arribar a l'indret de l'aturada, haurem vist afloraments dels materials carbonatats del Devonià.

Tot i això, molt sovint aquests materials es troben recoberts per terrenys neògens d'origen glaciar. Aquests materials detrítics, segons els indrets pertanyen al Pleistocè i també a I'Holocè.

\subsection{Parada 6. ELS ESTRETS, (Manyanet, actualment forma part del terme de Sarroca de Bellera, del Pallars Jussà i abans ho era del terme de Benes, de I’Alta Ribagorça). (Full 214).}

Després de realitzar l'aturada anterior, cal continuar baixant a peu. Així, ara ens anirem apropant als Estrets, per on podem fer una nova parada, després de baixar uns 150 metres més, invertint més de 30 minuts en fer-lo.

Com als recorreguts anteriors, en aquest tram. Hem continuat trobant afloraments dels materials paleozoics de l'ordovicià, del Silurià i del Devonià. Tots ells formen part dels Apilaments Antiformes de la Zona Axial Pirinenca, per on ens trobem situats des de l'inici del recorregut.

En aquest indret, el riu Manyanet, es va endinsant entre us afloraments dels materials carbonatats del Devonià. Així, el riu constitueix un congost entre els materials acabats d'esmentar. (fotografia 3). 


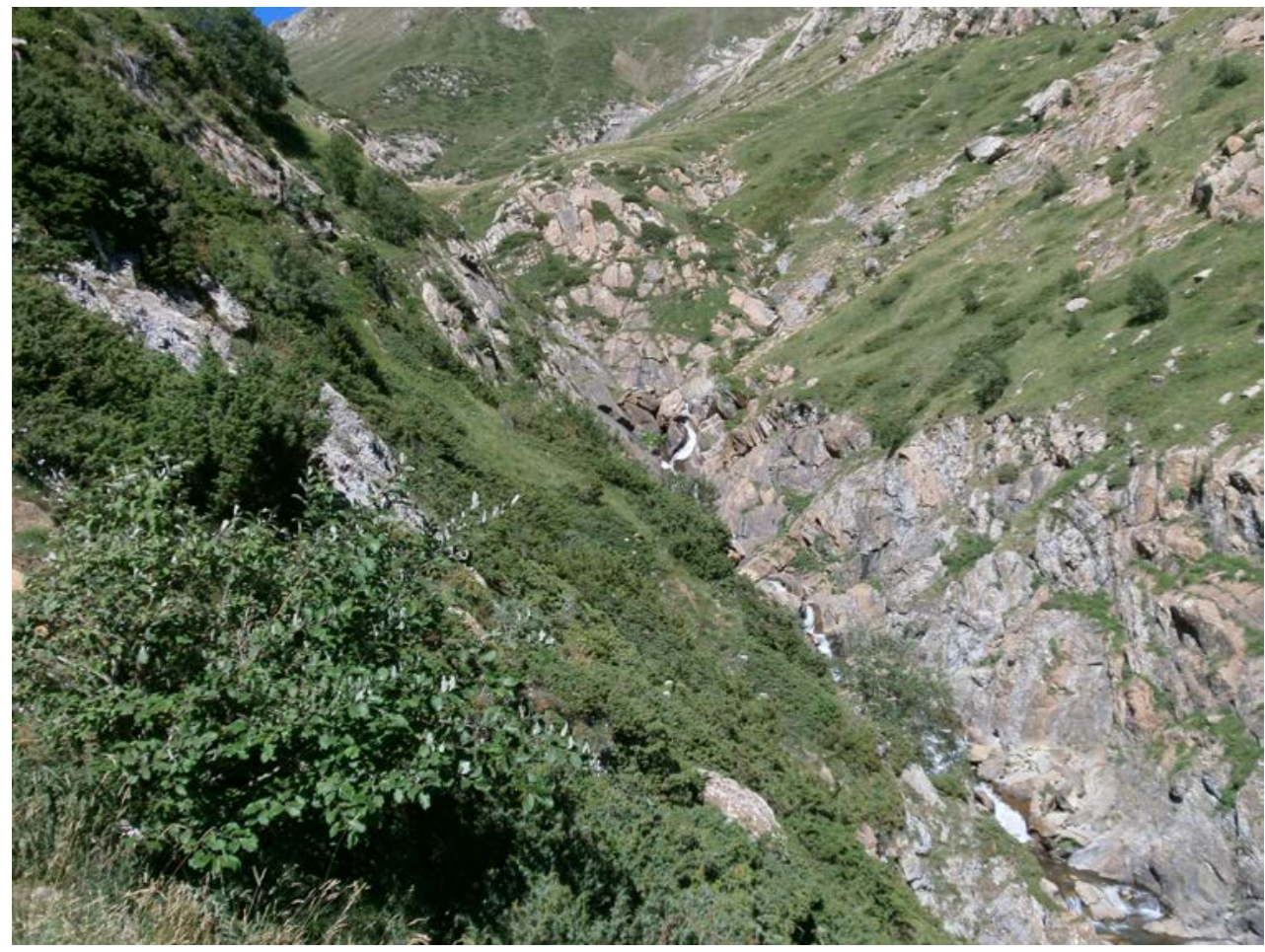

Fotografia 3. Els Estrets, Llevata. 9 d’agost del 2013

Cal dir que en aquest tram del recorregut, hem anat trobant afloraments dels materials paleozoics del Devonià. Entre aquests materials carbonats, és relativament fàcil trobar bons exemples d'esquistositat.

Alhora, es van trobant filons de quars. Aquests presenten diversos plecs ptigmàtics, alhora que es fàcil veure també "boudins" entre els filons dels materials quarcitics.

Per altra banda, es van veient bons elements de morfologia glacial, al llarg de bona part del recorregut per la zona dels estrets. (fotografia 4). 


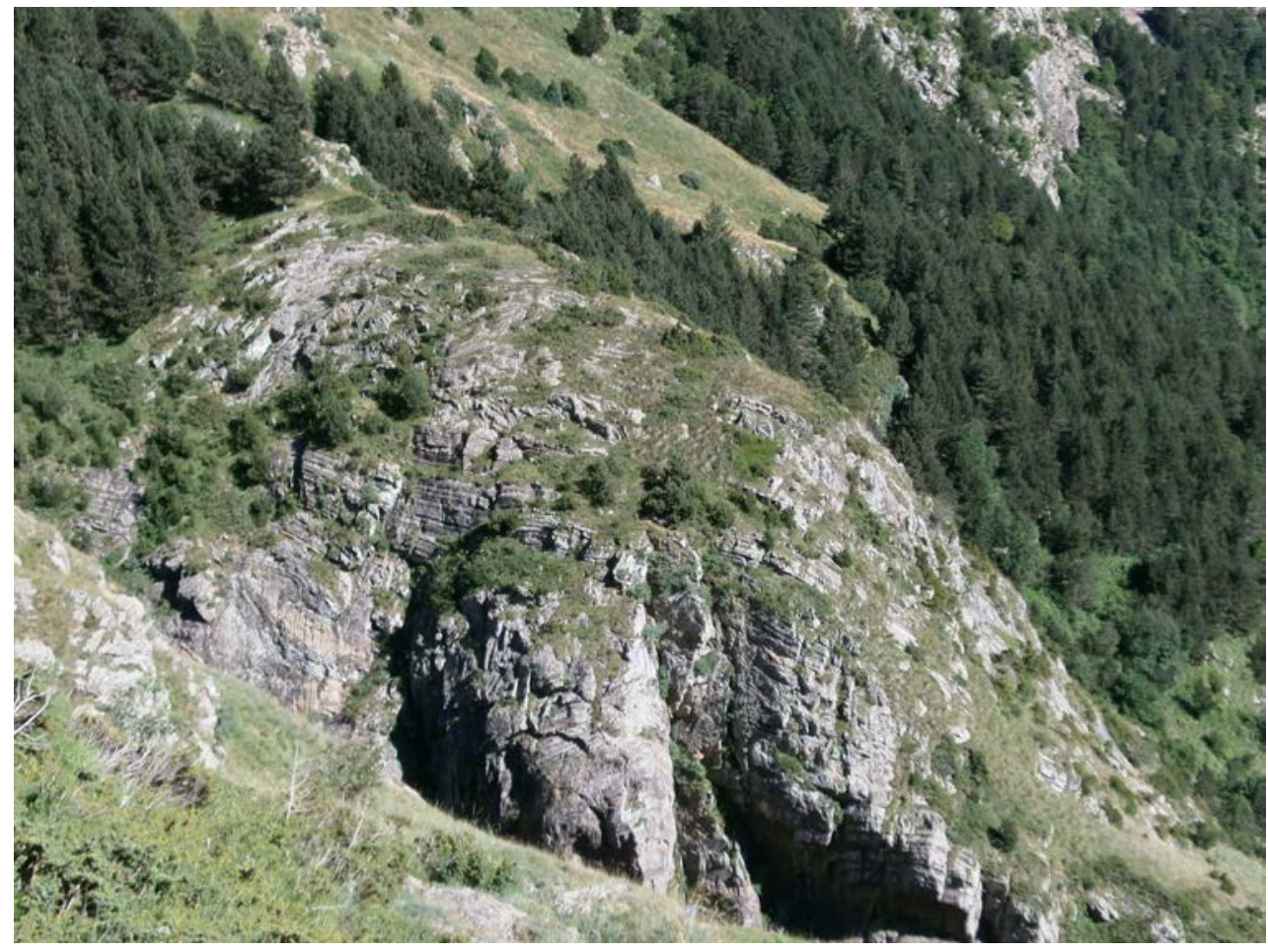

Fotografia 4. Umbrals glacials, amb exemples d'estries sobre ells. Pas de Llevata. 9 d'agost del 2013

\subsection{Parada 7 - CONDICIONAL. BORDA DEL CASTELL, (Manyanet, actualment forma part del terme de Sarroca de Bellera, del Pallars Jussà i abans ho era del terme de Benes, de l'Alta Ribagorça). (Full 214).}

Després de realitzar l'aturada anterior, cal continuar baixant a peu. Així, ara ens anirem apropant a la Borda del Castell, per on podem fer una nova parada, després de baixar uns 300 metres més, invertint més de 1 hora en fer-lo.

En aquest tram, hem trobat afloraments del Devonià, al llarg de tot el recorregut, que hem fet dintre de la Zona Axial Pirinenca, on ens trobem situats, des de l'inici del recorregut.

Com als recorreguts anteriors, molt sovint aquests materials es troben recoberts per terrenys detrítics neògens del Pleistocè i també de l'Holocè. 


\subsection{Parada 8. BARRANC DE LA COSTA, (Manyanet, actualment és del terme municipal de Sarroca de Bellera de la comarca del Pallars Jussà i antigament era del terme de Benes, de I’Alta Ribagorça). (Full 214).}

Des de la parada anterior, cal continuar cap el Sud, baixant sempre cap a Manyanet. Després de superar aquest darrer poble i abans d'arribar al de Mesull, farem una nova aturada al Barranc de la Costa, podem fer una nova aturada. Així, haurem efectuat un nu descens de prop de 300 metres, havent invertit prop de 1 hora en fer-lo.

En aquest recorregut, inicialment hem anat trobant els materials esmentats a les aturades anteriors. Així, hem anat trobant afloraments dels materials del Devonià, situant-nos sempre dintre de la Zona Axial Pirinenca.

En aquest indret, hi ha un aflorament dels nivells carbonatats nodulosos del Devonià, els quals formen par de l'anomenada Formació Manyanet. Aquesta es troba situada al trànsit del Devonià Inferior al Devonià Superior.

També haurem vist nivells de pissarres, les quals pertanyen a la Formació Vilaller. (fotografia 5).

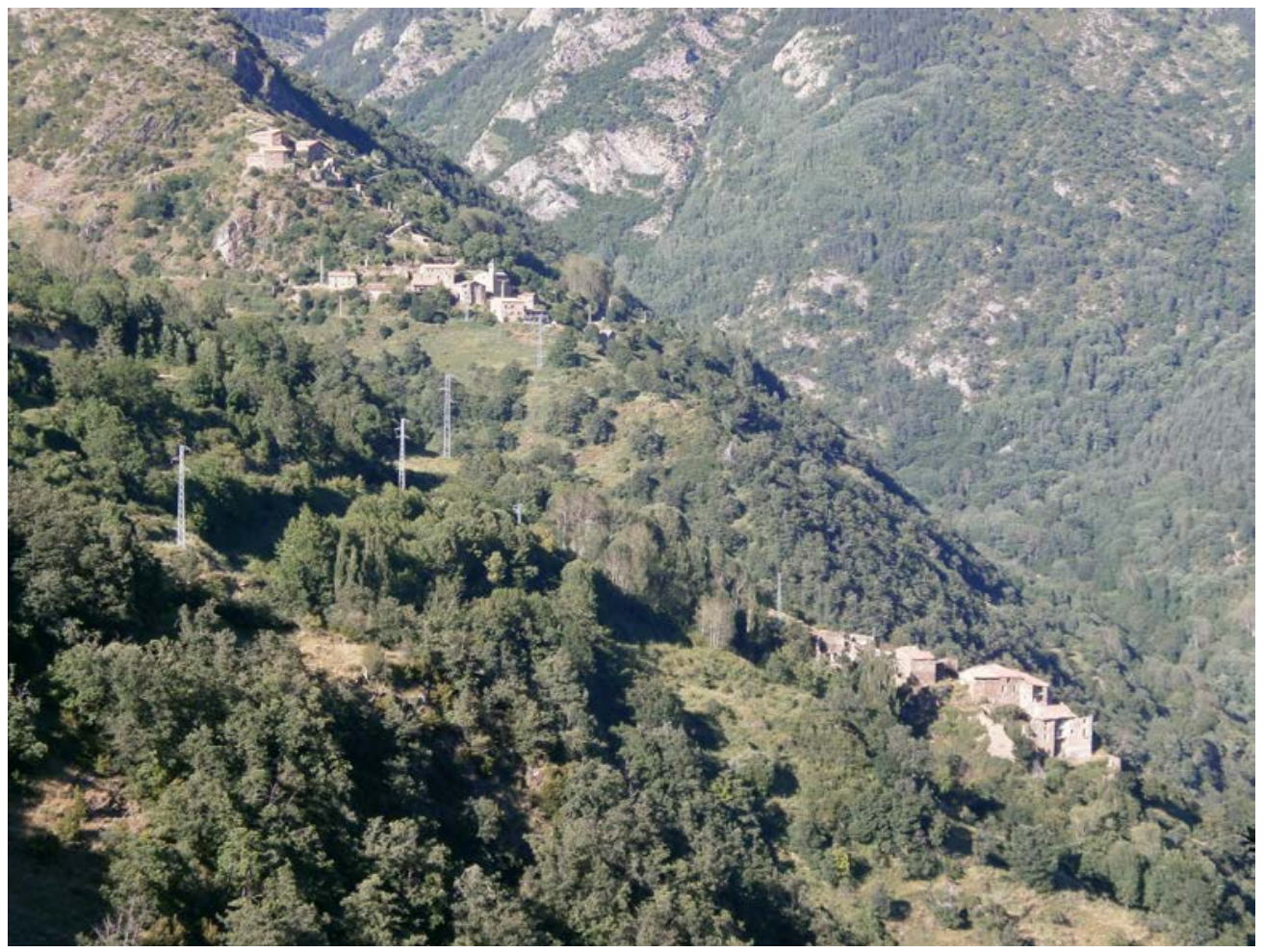

Fotografia 5. Manyanet i Mesull. Vall de Manyanet, 9 d'agost del 2013 
En aquest indret finalitza el recorregut de l'itinerari

\section{Bibliografia}

GUIMERÀ, J. et altri (1992).- Geologia (II). Història Natural dels Països Catalans. Vol. 2, 547 pag. Enciclopèdia Catalana, S.A. Barcelona.

MATA-PERELLÓ,J.M. (1991).- Els Minerals de Catalunya. Arxius de la Secció de Ciències de I'Institut d'Estudis Catalans, vol.47, 545 pag. Barcelona.

MATA-PERELLÓ,J.M. (2013a).- Recorregut de recerca de geològica i mineralògica per la comarca de l'Alta Ribagorça: des de Castelló de Tor a Boí, Taüll, al Pas d’Erta i al Pas de Llevata. Inèdit. 8 pàgines. Manresa.

MATA-PERELLÓ,J.M. (2013b).- Recorregut de recerca geològica i mineralògica per la comarca del Pallars Jussà: des de Xerallo a la Mola d'Amunt i a Manyanet. Inèdit. 10 pàgines. Manresa

MATA-PERELLÓ,J.M. (2013c).- Recorregut de recerca de geològica i mineralògica per les comarques de I'Alta Ribagorça i del Pallars Jussà: des de Taüll, al Pas de Llevata i a Manyanet. Inèdit. 10 pàgines. Manresa.

MATA-PERELLÓ, J.M. i SANZ BALAGUÉ, J. (1988).- Guia d’identificació de minerals. Edit. Parcir, 205 pàg. Manresa.

MATA-PERELLÓ, J.M. i SANZ BALAGUÉ, J. (1993).- Guia de Identificación de Minerales, adaptada fundamentalmente a la Península Ibérica. Edic. Parcir, 243 pag. Manresa

RIBA ARDERIU, O. et altri (1976).- Geografia Física dels Països Catalans, Edit. Ketres. Barcelona. 